\title{
Correction to: Co-delivery of nanoparticle and molecular drug by hollow mesoporous organosilica for tumor-activated and photothermal-augmented chemotherapy of breast cancer
}

\author{
Haixian Zhang ${ }^{1 \dagger}$, Feifei Song ${ }^{2 \dagger}$, Caihong Dong ${ }^{3^{*}}$, Luodan $\mathrm{Yu}^{4}$, Cai Chang ${ }^{1 *}$ and Yu Chen ${ }^{4^{*}}$ (D)
}

\section{Correction to: J Nanobiotechnol (2021) 19:290}

https://doi.org/10.1186/s12951-021-01025-w

Following publication of the original article [1], the authors identified an error in the supplementary information. The correct version of supplementary information is given in this erratum.

\section{Supplementary methods}

\subsection{In vitro DSF release of DSF@HMONs}

DSF@HMONs (5 mg) was encapsulated into a dialysis bag (molecular weight cut-off $=5 \mathrm{kDa}$ ), and then immersed in aqueous solution $(30 \mathrm{~mL})$. The release procedure was conducted in a shaking table $\left(100 \mathrm{rpm}, 37^{\circ} \mathrm{C}\right)$

The original article can be found online at https://doi.org/10.1186/s12951 021-01025-w.

*Correspondence: dong.caihong@zs-hospital.sh.cn; changc61@163.com; chenyuedu@shu.edu.cn

${ }^{\dagger}$ Haixian Zhang and Feifei Song contributed equally to this work

1 Department of Ultrasound, Department of Oncology, Fudan University

Shanghai Cancer Center, Shanghai Medical College, Fudan University,

200032 Shanghai, People's Republic of China

${ }^{3}$ Department of Ultrasound, Zhongshan Hospital, Fudan University

and Shanghai Institute of Medical Imaging, Shanghai 200032, People's Republic of China

${ }^{4}$ Materdicine Lab, School of Life Sciences, Shanghai University, Shanghai 200444, People's Republic of China

Full list of author information is available at the end of the article and the DSF-releasing amount was measured by UV-vis spectroscopy at $\lambda=480 \mathrm{~nm}$ at the given time point.

\subsection{In vitro photothermal effect of $\mathrm{CuS}$}

The photothermal performance of $\mathrm{CuS}$ was characterize by recording the temperature changes during laser irradiation with $808 \mathrm{~nm}$ (FLIR TM A325SC camera). CuS nanoparticles were dispersed in deionized water with different $\mathrm{Cu}$ concentrations $(12.5,25,50$, and $100 \mu \mathrm{g} / \mathrm{mL})$, which were then exposed to $808 \mathrm{~nm}$ laser irradiation at the laser-power density of $1.5 \mathrm{~W} / \mathrm{cm}^{2}$. In addition, the temperature increase of $\mathrm{CuS}$ aqueous solution at the $\mathrm{Cu}$ concentration of $50 \mu \mathrm{g} / \mathrm{mL}$ as irradiated by $808 \mathrm{~nm}$ laser at different power intensities $(0.75,1.0,1.25$, and $1.5 \mathrm{~W} /$ $\mathrm{cm}^{2}$ ) was tested.

\subsection{In vitro cytotoxicity assay of HMONs}

To evaluate in vitro cytotoxicity of HMONs, a standard CCK-8 viability assay was conducted. Varied concentrations $(0,6.25,12.5,25,50,100$ and $200 \mu \mathrm{g} / \mathrm{mL})$ of HMONs were co-incubated with $4 \mathrm{~T} 1$ cells pre-seeded in 96-well plants for $6 \mathrm{~h}$ and $24 \mathrm{~h}$. Then CCK-8 diluted by DMEM at a ratio of 1:10 was added into plates to test the cell viabilities at a wavelength of $450 \mathrm{~nm}$ after $60 \mathrm{~min}$ on a microplate reader. original author(s) and the source, provide a link to the Creative Commons licence, and indicate if changes were made. The images or other third party material in this article are included in the article's Creative Commons licence, unless indicated otherwise in a credit line to the material. If material is not included in the article's Creative Commons licence and your intended use is not permitted by statutory regulation or exceeds the permitted use, you will need to obtain permission directly from the copyright holder. To view a copy of this licence, visit http://creativecommons.org/licenses/by/4.0/. The Creative Commons Public Domain Dedication waiver (http://creativecommons.org/publicdomain/zero/1.0/) applies to the data made available in this article, unless otherwise stated in a credit line to the data. 


\section{Supplementary figures}

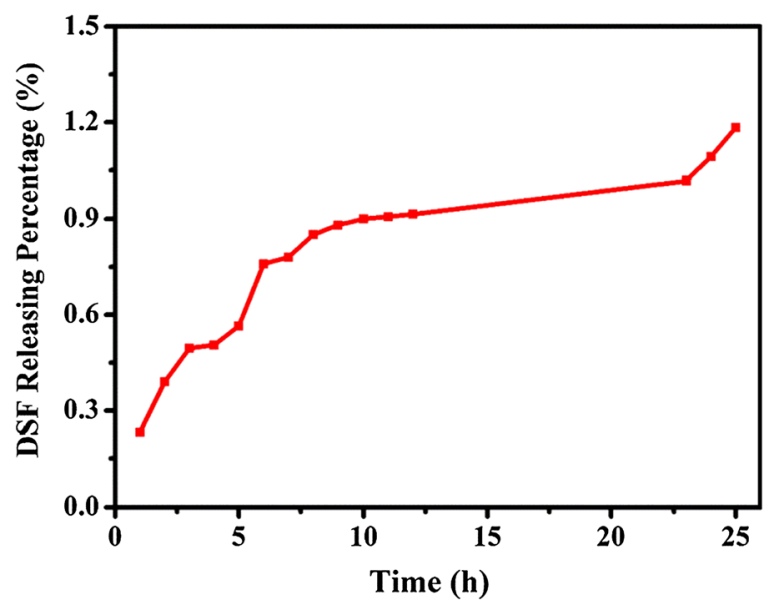

Figure S1. The releasing profile of DSF from DSF@ HMONs in aqueous solution

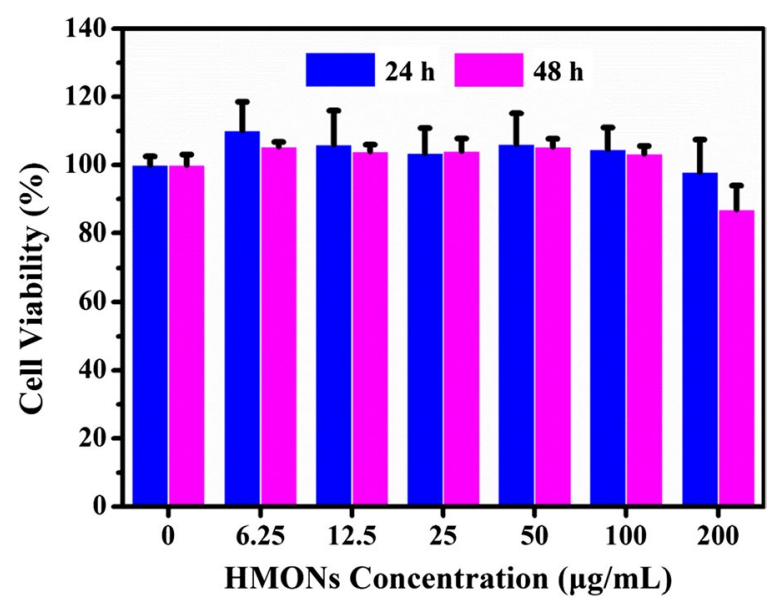

Figure S3. Relative cell viability of 4T1 cancer cells after incubation with different concentrations $(0,6.25,12.5$, $25,50,100$ and $200 \mu \mathrm{g} / \mathrm{mL}$ ) of HMONs for $24 \mathrm{~h}$ and $48 \mathrm{~h}$ a

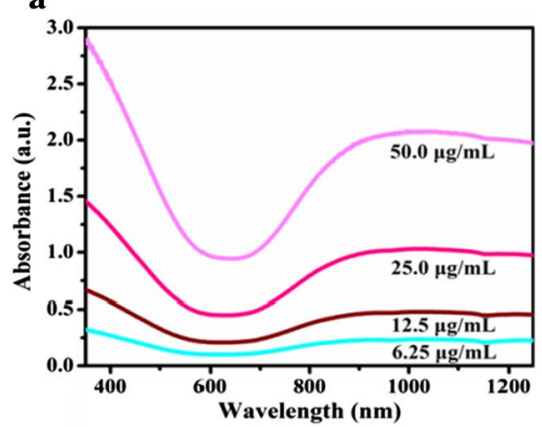

d

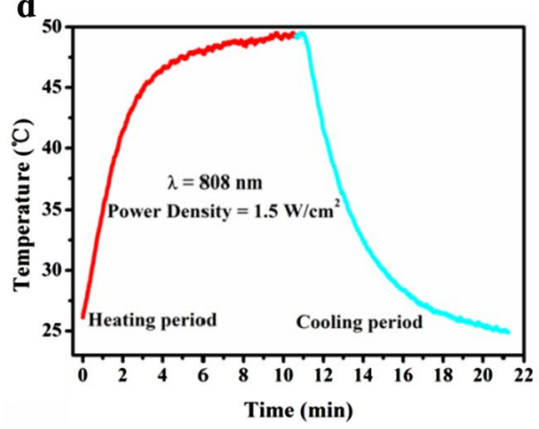

b

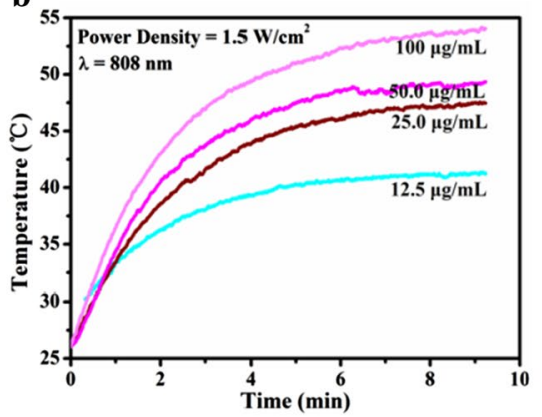

e

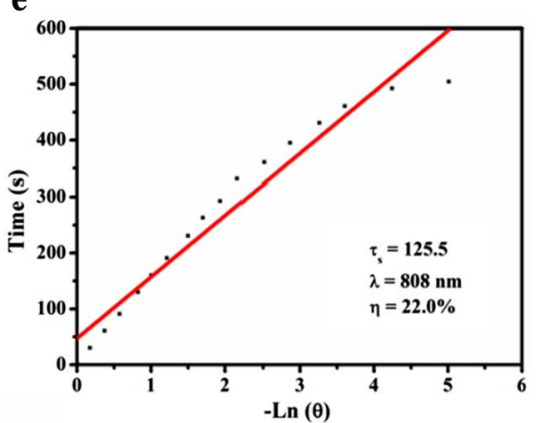

c

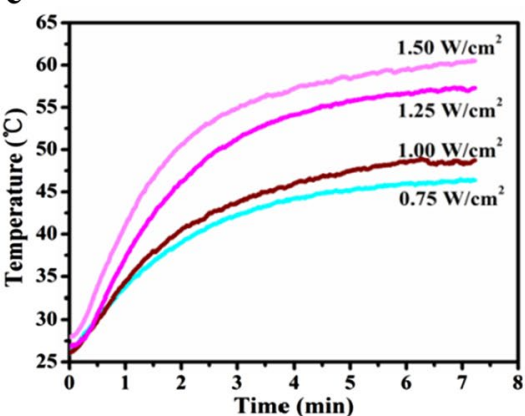

f

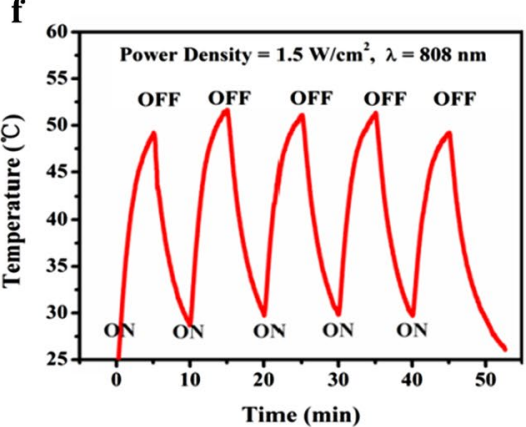

Figure S2. In vitro photothermal-conversion assessment of CuS. (a) UV-vis spectra of CuS at different concentrations $(6.25,12.5,25$ and $50 \mu \mathrm{g} / \mathrm{mL})$ in aqueous solution. (b) Temperature changes of CuS aqueous solution with NIR laser (808 nm, power density: $\left.1.5 \mathrm{~W} / \mathrm{cm}^{2}\right)$ irradiation at elevated concentrations $(12.5,25,50$, and $100 \mu \mathrm{g} / \mathrm{mL})$. (c) Photothermal-heating curves of $\mathrm{CuS}$ dispersed in aqueous solution irradiated by different power intensities $(0.75,1.0,1.25$ and $1.5 \mathrm{~W} / \mathrm{cm}^{2}$ ) of NIR laser at the wavelength of $808 \mathrm{~nm}$. (d) Photothermal performance of CuS dispersed in aqueous solution under NIR irradiation; the laser was turned off when the temperature was stable. (e) Time constant for heat transfer calculated from the cooling period. (f) Heating curve of $\mathrm{CuS}$ dispersed in water for five laser on/off cycles irradiated by $808 \mathrm{~nm}$ laser at the power intensity of $1.5 \mathrm{~W} / \mathrm{cm}^{2}$ 

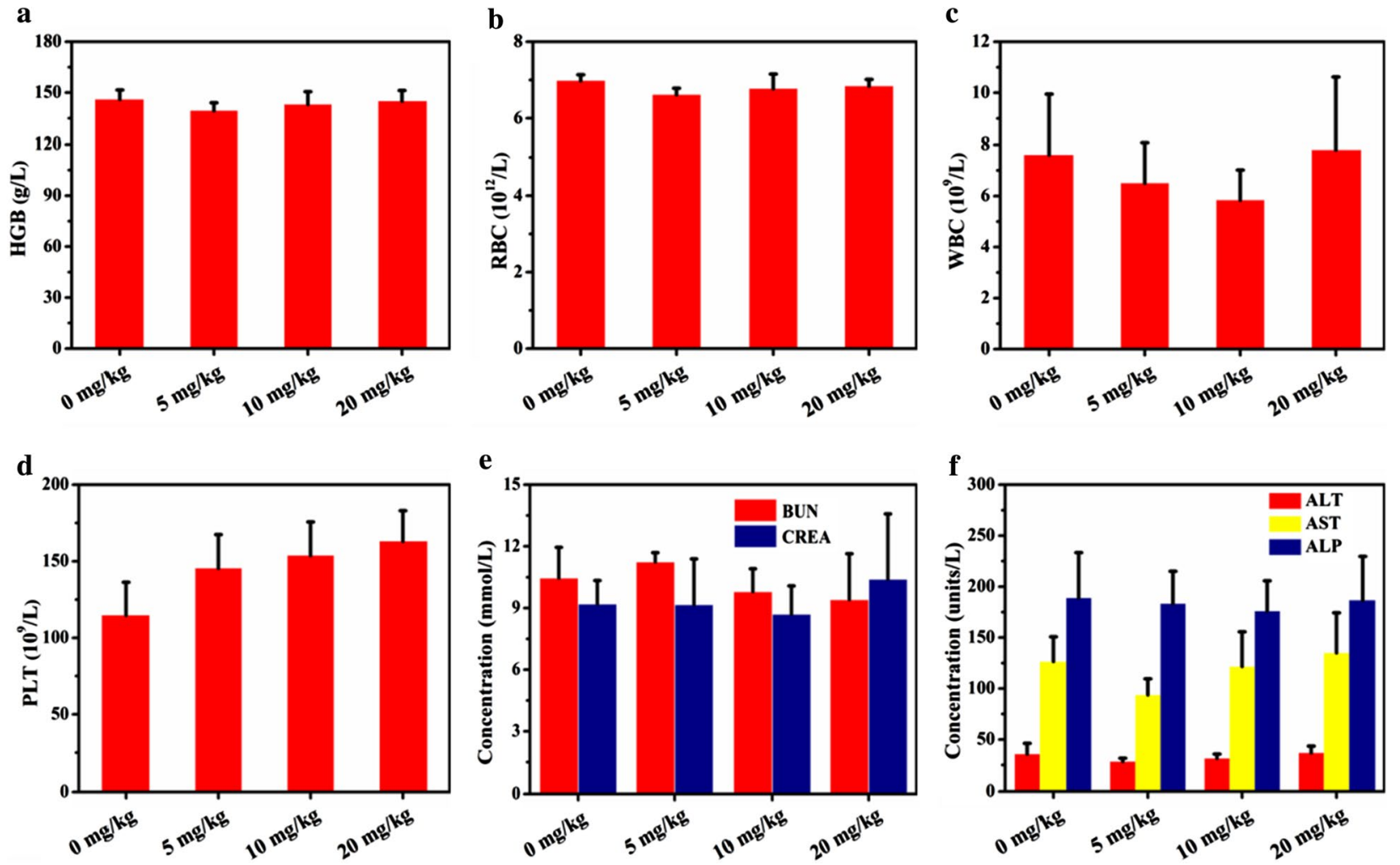

Figure S4. Blood routine examination and serum biochemical levels of mice treated with $0 \mathrm{mg} / \mathrm{kg}, 5 \mathrm{mg} / \mathrm{kg}, 10 \mathrm{mg} / \mathrm{kg}$, and $20 \mathrm{mg} / \mathrm{kg}$ of DSF@HCu. (a) Hemoglobin (HGB), (b) Red blood cell (RBC), (c) White blood cell (WBC), (d) Platelet (PLT), (e) Blood urea nitrogen (BUN) and creatinine (CREA), (i) Alanine transaminase (ALT), aspartate aminotransferase (AST) and alkaline phosphatase (ALP) levels of mice in all groups 


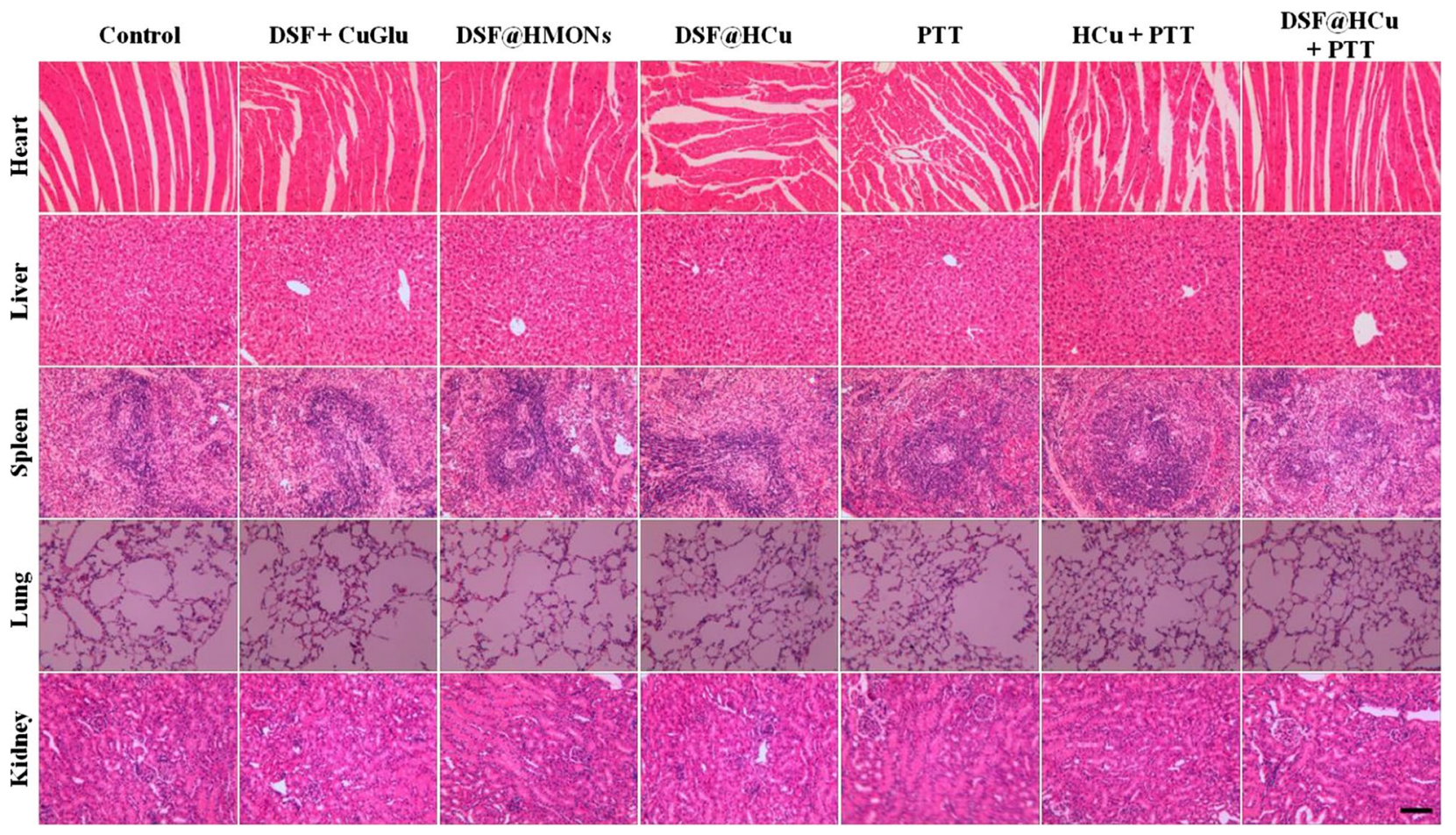

Figure S5. Histopathological examinations of major organs (heart, liver, spleen, lung and kidney) from mice after different treatments

The original article has been revised.

\begin{abstract}
Author details
'Department of Ultrasound, Department of Oncology, Fudan University Shanghai Cancer Center, Shanghai Medical College, Fudan University, 200032 Shanghai, People's Republic of China. ${ }^{2}$ Department of Pathology, Shanghai Tenth People's Hospital Affliated To Tongji University, 200072 Shanghai, People's Republic of China. ${ }^{3}$ Department of Ultrasound, Zhongshan Hospital, Fudan University and Shanghai Institute of Medical Imaging, Shanghai 200032, People's Republic of China. ${ }^{4}$ Materdicine Lab, School of Life Sciences, Shanghai University, Shanghai 200444, People's Republic of China.
\end{abstract}

Published online: 03 November 2021

\section{Reference}

1. Zhang H, Song F, Dong C, Yu L, Chang C, Chen Y. Co-delivery of nanoparticle and molecular drug by hollow mesoporous organosilica for tumor-activated and photothermal-augmented chemotherapy of breast cancer. J Nanobiotechnol. 2021;19:290. https://doi.org/10.1186/ s12951-021-01025-w.

\section{Publisher's Note}

Springer Nature remains neutral with regard to jurisdictional claims in published maps and institutional affiliations. 